\title{
CONSERVATIVE MANAGEMENT OF SPONTANEOUS UTERINE PERFORATION IN CASE OF PLACENTA ACCRETA DURING CAESAREAN SECTION: CASE REPORT.
}

Neha Patel, Jayun M. Joshi, Raxita Patel, Yamini Trivedi

1. Senior Resident, Department of Obstetrics \& Gynaecology, L. G. Hospital, Ahmedabad.

2. Assistant Professor, Department of Obstetrics \& Gynaecology, L. G. Hospital, Ahmedabad.

3. Associate Professor, Department of Obstetrics \& Gynaecology, L. G. Hospital, Ahmedabad.

4. Professor, Department of Obstetrics \& Gynaecology, L. G. Hospital, Ahmedabad.

\section{CORRESPONDING AUTHOR}

\section{Dr. Jayun Joshi}

24 Jagatjanani Society,

Behind Polytechnic, Ambawadi,

Ahmedabad- 380015.

E-mail: drjmjoshi@gmail.com

Ph: 00919427711313

ABSTRACT: BACKGROUND: The incidence of placenta accrete has increased 10 fold in the past 50 years and now occurs with a frequency of 1 per 2,500 deliveries. Women who have had 2 or more cesarean deliveries with anterior or central placenta previa have nearly a $40 \%$ risk of developing placenta accreta. An abnormally adherent placenta, although an uncommon condition, assumes considerable significance clinically because of morbidity and at times mortality from severe hemorrhage, uterine perforation, and infection. Placenta accrete occurring in an unscarred uterus is exceedingly rare. CASE PRESENTATION: A 25 year-old multigravida was admitted for emergency Caesarean Section at 36 weeks with the diagnosis of preeclampsia. There were 2 small uterine perforations seen on posterior wall of uterus. The placenta was found to be densely adherent to the posterior uterine wall. Piecemeal excision of the placenta as close as possible to the uterine lining was then performed. The perforations were sutured with interrupted stitches. CONCLUSION: Spontaneous uterine perforation associated with placenta accreta can be managed conservatively with suturing \& does not necessitate hysterectomy.

KEY WORDS: Placenta accreta, caesarean section, uterine perforation

INTRODUCTION: Placenta accrete is defined as abnormal adherence, either in whole or in part of the afterbirth to the underlying uterine wall. Placenta accrete and other pathological placentations (such as increta, percreta) are rare complications of pregnancy with potential life threatening and fertility threatening consequences. The incidence of placenta accrete has increased ten times over the last fifteen years ( 1 per 2500 deliveries), which reflects the increase in the rate of Caesarean Sections (9). Placenta accrete has become the most important cause of peripartum hysterectomy. A life threatening acute uterine inversion, uterine necrosis, uterine perforation and massive $\mathrm{PPH}$ can be caused by placenta accrete during caesarean section.

MATERIAL \& METHODS: A 25 year old, multigravida with previous history of 2 full term normal delivery with only one live issue \& one baby expired \& 1 spontaneous abortion followed 
by curettage before one year for retained products, was admitted in our Hospital with the signs of preeclampsia like headache \& vomiting at 36 weeks. She has been operated for emergency caesarean section for preeclampsia. She had two antenatal ultrasound examinations at some rural hospital showing a healthy foetus and posterior fundal placenta without any evidence of placenta accrete.

OBSERVATION \& RESULTS: The patient had delivered by lower segment Caesarean section of a healthy infant under spinal anaesthesia. The placenta was found to be densely adherent to the posterior uterine wall. The placenta was removed by 'piecemeal' excising as close as possible to the uterine lining. Most of the placental tissue was removed. There were 2 areas of uterine perforation of about $3 \times 2 \mathrm{~cm}$ and $2 \times 1 \mathrm{~cm}$ with surrounding area of blackening suggestive of necrosis found on posterior wall of uterus on upper segment. There was a small sample of tissue taken from the site of placental adherence and sent for histopathological examination. The uterus was closed in two layers. The perforations also closed with interrupted stitches. Tubal ligation was not done as her husband refuses to give the consent. Intra-abdominal drain was kept. The estimated blood loss was 2 litres and 2 units of blood were transfused during intra-operative and post-operative period. In addition, the patient was treated with intravenous oxytocin infusion, prostaglandins and antibiotics.

On the second post partum day, vaginal Doppler ultrasound scan showed significant amount of placental tissues with increased vascularity measuring $2.7 \times 6.6 \times 6.8 \mathrm{~cm}$ within the endometrial cavity.

The patient was discharged on the fifth post-operative day with a conservative management. A follow up Ultrasound scan after two weeks showed reduction of placental mass (Figure 1). In addition, there was significant decrease in serum beta HCG levels from $2300 \mathrm{u} / \mathrm{L}$ on day 1 to $13 \mathrm{u} / \mathrm{L}$ at four weeks post operatively. The patient remained with minimal vaginal bleeding without abdominal pain. She had two normal periods after stopping breastfeeding and was feeling well.

The biopsy report of the sent tissue confirmed the diagnosis(figure 2).

DISCUSSION: The term Placenta Accreta is used to describe any placental implantation in which there is abnormally firm adherence to the uterine wall. As the consequence of partial or total absence of the deciduas basalis and imperfect development of the fibrinoid layer, placental villi are attached to the myometrium. In Placenta Increta, it invades the myometrium and in Placenta Percreta, it penetrates through myometrium. The abnormal adherence may involve all of the cotyledons (total placenta accreta), a few to several cotyledons (partial placenta accreta), or a single cotyledons (focal placenta accreta).

The risk factors for placenta accreta include:

- Placenta previa with or without previous uterine surgery

- Prior myomectomy

- Prior cesarean delivery: 2 or more cesarean deliveries

- Asherman's syndrome

- Submucous leiomyomata

- Maternal age, older than 35 years

- Multiparity: gravida 6 or more 
The sonographic features suggestive of placenta accreta are: irregularly shaped placental lacunae (vascular spaces) within the placenta, thinning of the myometrium overlying the placenta, loss of the retroplacental "clear space", protrusion of the placenta into the bladder, increased vascularity of the uterine serosa-bladder interface, and on Doppler ultrasonography turbulent blood flow through the lacunae. It appears that MRI is no more sensitive than ultrasonography for diagnosing placenta accreta. Ultrasonography is readily available in most centers, whereas MRI is costly and relatively inaccessible. Therefore, at the present time, sonography is the primary imaging modality for diagnosing placenta accreta. However, when there is a posterior placenta accreta, ultrasonography may be less than adequate, and MRI may be superior to ultrasonography for this specific indication.

If clinically or sonographically the patient is suspected antenatally to be at risk of placenta accreta, appropriate management options should be considered, such as attempted conservative management or hysterectomy and counselling provided about potential sequelae. The traditional management is abdominal hysterectomy, but this operation terminates fertility and may have devastating psychological effects. However, in correct circumstances, a conservative approach may be suitable. It should be only considered in highly selected cases when blood loss is minimal and there is wish for fertility preservation.

For women who want to preserve their fertility the placenta should be left intact if possible after caesarean delivery as this approach lowers the risk of subsequent hysterectomy from $85 \%$ to $15 \%$. For women who have completed their family, hysterectomy with placenta left in situ is preferable to lower the maternal morbidity rates.

This case report involved conservative management. Peripartum hysterectomy was avoided and the aim was to preserve fertility. Prophylactic antibiotics, post partum oxytocics and the use of prostaglandins post operatively helped to prevent further post partum haemorrhage.

When a patient is initially opted for conservative management, the possibility of recurrence should be discussed. Furthermore, placentation should be carefully monitored for recurrence in any subsequent pregnancy.

CONCLUSION: We suggest an alternative approach for managing uterine perforation caused by placenta accreta that involved conservative management. This way hysterectomy was avoided and fertility was preserved.

\section{REFERENCES:}

1. Kirknen P, Helin-Martikainen HL, Vanninen R, Partnen K, Placenta accreta: imaging by gray-scale and contrast-enhanced color Doppler sonography and magnetic resonance imaging. J Clin Ultrasound 1998; 26:90-94

2. Resnik R. Diagnosis and management of placenta accreta. ACOG Clin Rev 1999; 4 (2): 8-9

3. Comstock $\mathrm{CH}$. Antenatal diagnosis of placenta accreta: a review. Ultrasound Obstet Gynecol. 2005;26:89-96.

4. American College of Obstetrics and Gynaecology ACOG committee opinion: Placenta accreta. Number 266, January 2002 Committee on Obstetrics Practice.

5. Finberg HJW: Placenta accreta prospective sonographic diagnosis in patients with placenta praevia and prior Caesarian section. J Ultrasound Med 1992, 11(7):333344. 
6. Armstrong CA, Harding S, Dickinson JE: Clinical aspects and conservative management of placenta accreta. Obstet and Gynaecol 2004, 6:132-137.

7. Kayem G, Davy C, Goffinet F, Thomas C, Clément D, Cabrol D: Conservative versus extirpative management in cases of placenta accreta. Obstet Gynecol 2004, 104:531-536.

8. Kayem G, Clément D, Goffinet F: Recurrence following conservative management of placenta accreta.Inter J GynecolObstet 2007, 99(2):142-143.

9. Wu S, Kocherginsky M, Hibbard JU. Abnormal placentation: twenty-year analysis. Am J Obstet Gynecol 2005 May;192(5):1458-61.

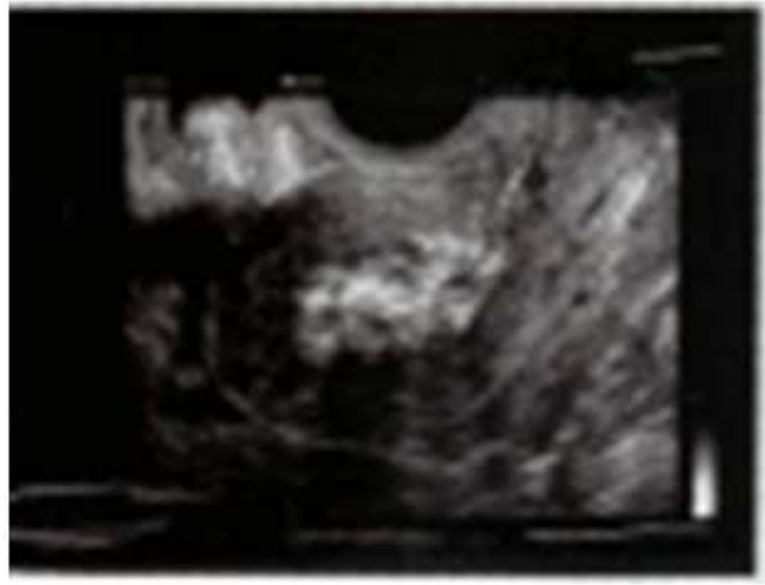

Figure 1: Retained placental product 2 weeks Post CS

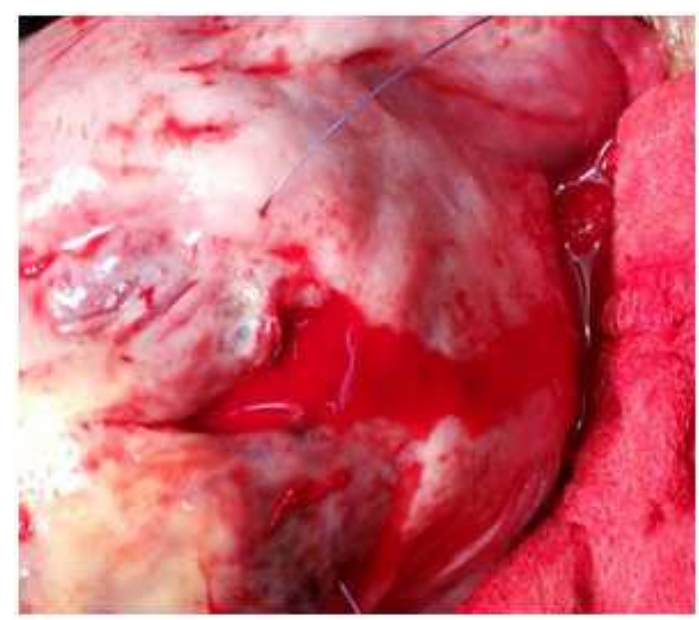

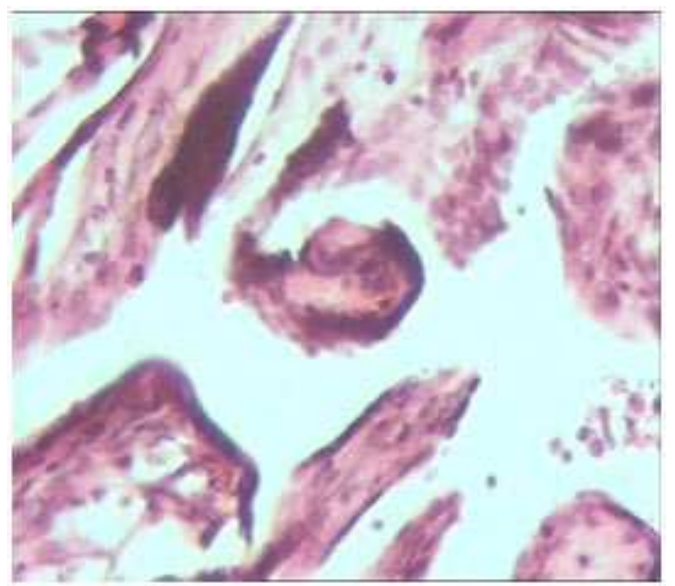

Figure 2: Histopathological picture showing placenta accrete

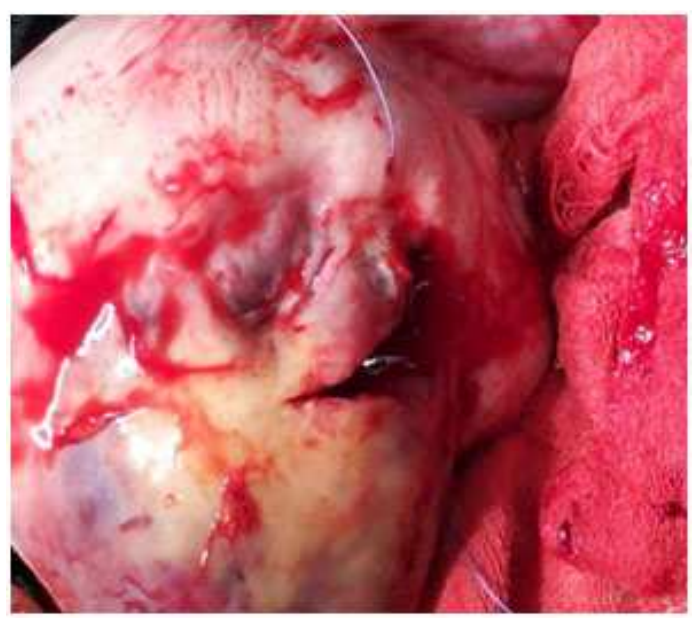

Figure $3 \& 4$. Perforation in posterior uterine wall with surrounding necrosis 